\title{
Flow Focusing in Unsaturated Fracture Networks: A Numerical Investigation
}

\author{
Keni Zhang ${ }^{*}$ Yu-Shu Wu, G. S. Bodvarsson, and Hui-Hai Liu
}

Earth Sciences Division, Lawrence Berkeley National Laboraotry, MS 90-1116, 1 Cyclotron Rd, Berkeley, CA, 94720. * Corresponding author (kzhang@lbl.gov) 


\section{ABSTRACT}

A numerical modeling study is presented to investigate flow-focusing phenomena in a largescale fracture network, constructed using field data collected from the unsaturated zone of Yucca Mountain, Nevada, the proposed repository site for high-level nuclear waste. The twodimensional fracture network for an area of $100 \mathrm{~m} \times 150 \mathrm{~m}$ contains more than 20,000 fractures. Steady-state unsaturated flow in the fracture network is investigated for different boundary conditions and rock properties. Simulation results indicate that flow paths are generally vertical, and that horizontal fractures mainly provide pathways between neighboring vertical paths. In addition to fracture properties, flow-focusing phenomena are also affected by rock-matrix permeability, with lower matrix permeability leading to a high degree of flow focusing. The simulation results further indicate that the average spacing between flow paths in a layered system tends to increase and flow tends to becomes more focused, with depth.

\section{INTRODUCTION}

It is widely recognized that fractures play an important role in flow and transport process through unsaturated geologic strata. Because fracture permeability is generally much greater than rock matrix permeability, fracture networks have the potential for being highly effective pathways for conducting fluid. Recently, the need to investigate flow and transport in the unsaturated zone (UZ) of Yucca Mountain, Nevada, the proposed permanent storage underground facility for geological disposal of high-level nuclear waste, has generated intensive research interest in modeling flow and transport processes in unsaturated fractured rocks. Different conceptual 
models have been proposed for handling water flow and tracer transport in the UZ at Yucca Mountain. Modeling approaches used in characterizing fracture flow in general include (1) the continuum model, such as the effective continuum model (ECM) and dual-permeability models (e.g., Wu et al., 1999), (2) discrete-fracture models (e.g., Rasmussen, 1987; Kwicklis and Healey, 1993; Zimmerman and Bodvarsson, 1996; Liu et al., 2002), and (3) other models with discrete geologic features to study discrete flow processes (e.g., Finsterle, 2000). One of the main purposes of these modeling approaches is to determine flow paths and to examine flow focusing in complex fractured media.

Focused flow paths exist in the unsaturated rock of the Yucca Mountain site. For example, elevated levels of ${ }^{36} \mathrm{Cl}$ originating from atmospheric nuclear tests conducted in the 1950s and 1960s were found at several locations in an underground tunnel at the site (Fabryka-Martin et al., 1996), an indication of fast flow behavior. Flow focusing within well-connected fracture networks play an important role in controlling distribution of percolation fluxes through highly fractured tuffs (such as in the Topopah Spring welded tuff (TSw) unit, which will potentially house the repository drifts). Flow-focusing phenomena and discrete flow paths in the TSw unit are thus considered to be of significant importance to potential repository performance (Pruess, 1999).

Because the fracture geometry and connectivity of site-specific fractured rock is complex, flow behavior through unsaturated fractures is difficult to characterize for a given site (Bodvarsson, et al., 2003). Even with the significant progress made in the last two decades, flow processes in unsaturated fractured rock are currently still poorly understood. This poor understanding results 
mainly from technical difficulties in observing details of flow processes and accurately describing such phenomena within fractured rocks. However, flow processes occurring at this scale are importance to many field-scale applications. For the Yucca Mountain site, detailed knowledge of UZ flow processes is needed to predict the degree of flow focusing, which is essential for assessing the performance of the proposed nuclear waste repository.

In recent years, through field studies as well as mathematical simulations considerable progress has been made in understanding flow-focusing processes within unsaturated fractured rocks. The conventional approach for describing flow in partially saturated fractured media employs macroscale continuum concepts (Peters and Klavetteer, 1988). Those approaches use large-scale volume averaging for homogenizing heterogeneous fracture and matrix permeabilities. Some researchers have conceptualized heterogeneous fractured media with a stochastic spatial distribution of fracture permeability (Gauthier et al., 1992; Pruess, 1998; Bodvarsson, et al. 2002). For example, Pruess (1998) proposed a continuum-based mechanistic model for investigating localized flow. In his model, water seepage under different boundary conditions in a small range of heterogeneous fractured media is investigated. Bodvarsson et al. (2003) used a similar approach to investigate the development of flow focusing and discrete paths that may occur through unsaturated fractures within the TSw unit. To quantify flow-focusing behavior, their stochastic fracture-continuum models incorporated fracture data measured from the welded tuffs to study flow-allocation mechanisms and patterns.

In this study, we present a numerical investigation of steady flow paths and flow focusing in large-scale, two-dimensional, unsaturated discrete-fracture networks. Previous studies of flow 
and transport in fracture networks are limited to a small number of fractures (Kwichlis and Healy, 1993; Zimmerman and Bodvarsson, 1996), a relatively small scale (Liu et al., 2002), or a regular pattern of fracture distribution (Therrien and Sudicky, 1996; Liu and Bodvarsson, 2001). Our model will consider more sophisticated fracture-network geometry. The fracture network under study consists of tens of thousands of fractures and fracture distribution in this network is governed by statistical information derived from field-measured fracture data. Compared to previous models, our new model is able to more realistically represent unsaturated flow behavior at field scale.

The primary objective of this work is to improve our understanding of discrete flow paths through unsaturated fracture networks as well as to present a methodology for constructing fracture networks using fracture data collected from the TSw unit of the Yucca Mountain site. A thorough understanding of discrete fracture flow in the TSw unit is helpful for predicting the performance of the proposed repository, because water percolation conditions in this unit cannot be readily measured at the site, and these have to be estimated using a model. On the other hand, other simplified modeling approaches are in general unable to capture such localized and discrete flow phenomena. In this paper, we try to answer the following questions: How may flow paths develop in the randomly distributed fracture network? How do rock matrix and infiltration rate (on the top boundary) influence flow patterns in the fracture networks? And what is the relation between flow focusing and boundary conditions? 


\section{CONSTRUCTION OF THE FRACTURE NETWORK}

There are several ways to computationally construct a fracture network (Chilès and de Marsily, 1993). For this study, we have constructed two-dimensional, vertical-cross-section fracture networks directly using field-mapping data, including field-measured fracture density, trace lengths, and orientations. For simplicity, each fracture in the network is randomly distributed. However, generation of the fracture network is conditioned by statistical information from field measurement data. The statistical properties of the generated fracture network reflect the properties of actual fracture distribution in the study domain.

The following numerical procedure is used to construct the fracture networks in this study. First, a point is randomly generated within a vertical cross section. Second, the randomly generated point is used as the middle point of the fracture or line element to create a fracture. The length of the fracture is also randomly determined from 10 groups of fractures that have different trace lengths and different probabilities of occurrence, determined from statistics of measured fracture data. Orientation or direction of the fracture is then determined in the same way as its length, (i.e., based on the measurements). Orientation and trace length are considered to be independent in generating the fracture network. At the same time, the fracture aperture is computed as a function of its trace length. Third, iterations of the above two steps are performed to achieve a desired fracture density. If the study domain consists of multiple layers, this procedure needs to be repeated to generate a fracture network for each layer. 
To quantify flow-focusing behavior, we have developed discrete-fracture models to incorporate fracture data measured specifically from the bottom of the Paintbrush nonwelded (PTn) unit (the geological unit immediately above the TSw) to the potential repository horizon. In this study, a fracture network with a size of $100 \mathrm{~m} \times 150 \mathrm{~m}$ is generated to represent the highly fractured TSw unit, including subunits TSw31, TSw32, TSw33, TSw34, and TSw35 (Wu et al., 1999). The five subunits from TSw31 to TSw35 have a thickness of 2.0, 40.0, 65.0, 38.0, and $5.0 \mathrm{~m}$, respectively (Figure 1). The lengths and orientations of generated fractures are consistent with statistical data from 15,290 fractures, collected from detailed line surveys in underground tunnels for these units. Table 1 shows the lengths for different fracture groups and their corresponding percentage (portion) for different units. Note that fractures with trace lengths smaller than $0.23 \mathrm{~m}$ were not considered in this study. Small fractures with trace lengths shorter than this cutoff probably contribute little to global fluid flow in the fracture network and therefore are ignored here. In addition, only a limited number of fracture data for TSw35 unit are available, and therefore the percentages presented in the table for different trace lengths of that unit may certain some uncertainty.

Table 1. Fracture length and percentage (portion) used for generating fracture networks

\begin{tabular}{|c|c|c|c|c|c|c|c|c|c|c|}
\hline \multirow[b]{2}{*}{$\begin{array}{c}\text { Group } \\
\#\end{array}$} & \multicolumn{2}{|l|}{ TSw31 } & \multicolumn{2}{|l|}{ TSw32 } & \multicolumn{2}{|l|}{ TSw33 } & \multicolumn{2}{|l|}{ TSw34 } & \multicolumn{2}{|l|}{ TSw35 } \\
\hline & $\begin{array}{l}\text { Length } \\
\text { (m) }\end{array}$ & $\begin{array}{l}\text { Percent } \\
(\%)\end{array}$ & $\begin{array}{l}\text { Length } \\
\text { (m) }\end{array}$ & $\begin{array}{l}\text { Percent } \\
(\%)\end{array}$ & $\begin{array}{l}\text { Length } \\
\text { (m) }\end{array}$ & $\begin{array}{l}\text { Percent } \\
(\%)\end{array}$ & $\begin{array}{l}\text { Length } \\
\text { (m) }\end{array}$ & $\begin{array}{l}\text { Percent } \\
(\%)\end{array}$ & $\begin{array}{l}\text { Length } \\
\text { (m) }\end{array}$ & $\begin{array}{l}\text { Percent } \\
(\%)\end{array}$ \\
\hline 1 & 0.5 & 31.86 & 0.7 & 22.71 & 0.5 & 23.29 & 0.7 & 26.72 & 1.2 & 15.79 \\
\hline 2 & 0.7 & 11.99 & 1.5 & 31.39 & 0.8 & 18.51 & 1.2 & 18.62 & 1.6 & 18.42 \\
\hline 3 & 0.9 & 13.88 & 2.5 & 16.02 & 1.5 & 25.22 & 1.7 & 19.20 & 2.0 & 15.79 \\
\hline 4 & 1.1 & 10.73 & 3.5 & 8.77 & 2.5 & 11.58 & 2.5 & 17.75 & 2.6 & 5.26 \\
\hline 5 & 1.3 & 7.57 & 4.5 & 7.82 & 3.5 & 7.99 & 3.5 & 8.27 & 3.5 & 7.89 \\
\hline 6 & 1.5 & 4.73 & 6.0 & 6.31 & 5.0 & 6.75 & 4.5 & 3.90 & 4.5 & 5.26 \\
\hline 7 & 2.0 & 10.09 & 8.5 & 3.30 & 7.0 & 2.41 & 5.5 & 2.16 & 5.5 & 7.89 \\
\hline 8 & 3.0 & 5.05 & 11.5 & 1.04 & 10.0 & 1.10 & 7.0 & 1.80 & 7.5 & 7.89 \\
\hline 9 & 5.0 & 3.79 & 14.5 & 1.13 & 15.0 & 1.31 & 10.0 & 0.94 & 15.0 & 10.53 \\
\hline 10 & 9.5 & 0.32 & 18.0 & 1.51 & 23.0 & 1.72 & 15.0 & 0.62 & 20.0 & 5.26 \\
\hline
\end{tabular}


Fracture density is an important parameter in constructing a fracture network. Measured line densities for the five units are $2.2,1.1,0.81,4.3$, and 3.2. The line density reflects the average number of fractures along a surveying line. Using the measured line density to generate twodimensional fracture networks with different random seeds, we find, in many cases, no globally connected flow path from top to bottom. One possible explanation for this is that because a fracture network is in reality three-dimensional, using measured fracture line density to generate fracture network in two dimensions may lead to a lower connectivity than in the real fracture system. In this study, the two-dimensional model is in fact a three-dimensional model with a unit thickness. In this case, fracture area density should be used to instead the line density for generating the network. Fracture area density is defined as the number of fractures distributed over a unit area in the horizontal direction. The field-measured fracture line density can be converted to area density through a numerical scheme.

Fracture area density is determined by counting the number of fractures per unit of horizontal area. To determine the fracture area density for a geological unit, we generated a horizontal fracture network assuming that the network has the same line density and trace length distribution as its corresponding two-dimensional vertical cross section, which is provided by field measurement data. Fracture direction in the horizontal fracture network is randomly distributed. We construct a fracture network $1 \mathrm{~m}$ in width and $100 \mathrm{~m}$ in length for each geological unit (an area of 100 square meters). The area density is obtained by dividing the total number of fractures of the network by 100 . Table 2 gives the field-measured line density and computed area density for all units. 
Table 2. Fracture line density and area density for different units

\begin{tabular}{|l|l|l|}
\hline Unit Name & $\begin{array}{l}\text { Line Density } \\
\text { (\# of Fractures } / \mathrm{m} \text { ) }\end{array}$ & $\begin{array}{l}\text { Area Density } \\
\text { (\# of Fractures } / \mathrm{m}^{2} \text { ) }\end{array}$ \\
\hline TSw31 & 2.2 & 4.55 \\
\hline TSw32 & 1.1 & 1.60 \\
\hline TSw33 & 0.81 & 1.37 \\
\hline TSw34 & 4.3 & 6.67 \\
\hline TSw35 & 3.2 & 4.08 \\
\hline
\end{tabular}

Based on the fracture area densities presented in Table 2 and fracture statistical information of these units, a randomly distributed fracture network is generated (Figure 1). This fracture network consists of 20,707 fractures, 303 of which connect to the top boundary. About $28 \%$ of the fractures are isolated and have no connection to the global fracture network system connected to top infiltration sources. These fractures may make little contribution to the global flow on the model scale. Figure 2 shows a fracture network consisting of those fractures that are connected or intersected to the globally connected paths.

Fracture aperture, another important geometric parameter for fracture flow, determines the permeability of a parallel-plate fracture (de Marsily, 1986). It has been found that the aperture of a fracture filled with calcite or another material is strongly related to its trace length (Chilès and de Marsily, 1993). In our study here, we use a correlation provided by Liu and Bodvarsson (2001) to determine fracture aperture:

$$
b=c L^{d}
$$

where $b$ is the fracture average aperture, $L$ is its trace length, and $c$ and $d$ are empirical constants. Based on air-permeability and fracture-density data from the TSw unit, Liu and Bodvarsson (2001) estimated the constants $c$ and $d$ to be $1.008 \times 10^{-4}$ and 0.317 , respectively. We use these 
two constants and the trace length of the 10 groups of fractures to determine their corresponding average fracture aperture.

\section{FLOW SIMULATION}

The simulation domain is considered to be a medium of the superposition of fracture network on porous matrix, i.e., fracture-matrix interaction is taken into account in the discrete-fracture model. A similar approach has been used by Sudicky and McLaren (1992), Zhang and Woodbury (2002), and others. Unlike the previous discrete-fracture approach, our new approach uses a fracturematrix interaction scheme analogous to the dual-permeability approach (e.g., Pruess et al, 1999), in which, each fracture element is associated with only one matrix element where the fracture element is located. Fracture-matrix flow between the fracture element and its corresponding matrix gridblock is approximated as quasi-steady, with the rate of interflow proportional to the difference in local average pressures (Warren and Root, 1963). However, unlike the traditional dual-permeability methodology, our new approach allows each porous matrix block to be associated with more than one fracture element or with no fracture element. This new conceptual model thus combines the advantages of discrete-fracture and dual-permeability approaches.

The model involves more than 140,000 elements and 300,000 connections. In it, the fracture network is discretized into 126,432 linear elements that have a maximum length of $1 \mathrm{~m}$. The intersection point of any two fractures is treated as an element. The volume of these intersection elements is possibly extremely small. In fact, the volume of the fracture elements may vary over 
several orders of magnitude. The background matrix rock is discretized into 15,000 blocks, with a uniform size of $1 \times 1 \mathrm{~m}$.

Previous theoretical and experimental work suggests that the relative permeability and capillary pressure behavior of fractures is similar to that of highly permeable media with intergranular porosity (e.g. Pruess and Tsang, 1990; Persoff and Pruess, 1995). As a result, the constitutive relationships of the van Genuchten model (1984) are selected for the calculation. Liu and Bodvarsson (2001) provide a detailed discussion of this issue. Input parameters for fractures include fracture permeability, van Genuchten $\alpha$ and $m$ parameters, porosity, and interface area. We adopt the same scheme as discussed by Liu and Bodvarsson (2001) for computing fracture permeability and van Genuchten $\alpha$ parameter. Parameter $m$ is an index of aperture size distribution for an individual fracture and is given a value of 0.633 in this study. Residual saturation $S_{r}$ and the satiated saturation $S_{s}$, which will be used in the van Genuchten model, are assigned values of 0.01 and 1 , respectively. A corresponding set of parameters is required for matrix blocks, which is provided in $\mathrm{Wu}$ et al. (1999). Rock matrix properties are estimated through inverse modeling and model calibration. In the parameter estimation studies, several sets of rock properties are obtained, due to different modeling conditions. We use the set of rock properties given in Table 3 .

Table 3. Rock properties for matrix used in this study ${ }^{*}$

\begin{tabular}{|l|l|l|l|l|}
\hline Model Layer & $k\left(\mathrm{~m}^{2}\right)$ & $\alpha\left(\mathrm{Pa}^{-1}\right)$ & $M$ & $\phi$ \\
\hline TSw31 & $5.9 \mathrm{E}-18$ & $3.13 \mathrm{E}-03$ & 0.278 & 0.053 \\
\hline TSw32 & $3.2 \mathrm{E}-16$ & $1.89 \mathrm{E}-02$ & 0.269 & 0.157 \\
\hline TSw33 & $2.3 \mathrm{E}-17$ & $5.97 \mathrm{E}-03$ & 0.280 & 0.154 \\
\hline TSw34 & $7.5 \mathrm{E}-19$ & $6.41 \mathrm{E}-04$ & 0.325 & 0.110 \\
\hline TSw35 & $3.1 \mathrm{E}-17$ & $2.63 \mathrm{E}-03$ & 0.242 & 0.131 \\
\hline
\end{tabular}

* In the table, $k$ is matrix permeability, $\alpha$ is van Genuchten's parameter (van Genuchten, 1980) of capillary pressure for matrix, $m$ is van Genuchten's parameter of retention curves, and $\phi$ is effective porosity. 
Flow simulations are carried out by applying water infiltration at various constant rates at the top of the fracture network (shown in Figure 2). Because of the strong heterogeneities and complex fracture connections present in fractures along the top boundary, it is impossible to simply distribute desired infiltration rates uniformly over all fractures crossing the top boundary. In response to this limitation, we accomplish infiltration by attaching an additional gridblock to the top of the fracture network. The entire top boundary of the network is connected to this single block, and a prescribed infiltration rate is applied to it. As water is injected into this block, water eventually flows into the fractures beneath the block. This outflow will in general partition nonuniformly among the fractures. After a rapid initial transient, this infiltration block will reach a steady flow condition. In this way, a constant infiltration rate is applied to the top boundary of the fracture network. The infiltrating water first enters into fractures and then partially imbibes into matrix blocks. Side boundaries are considered impermeable, and a free-drainage condition is imposed at the bottom boundary.

Steady-state unsaturated water flow through the fracture network and rock matrix system is simulated using the TOUGH2_MP code (Zhang et al., 2001), a parallel version of the TOUGH2 code (Pruess, 1991). Because randomly distributed fractures can lead to an extremely complex element connection system, and because elements have large differences in volume, numerical difficulties can arise, requiring intensive computational effort. For our model, we have found it necessary to use efficient numerical methods to perform the simulations. Specifically, one of the solutions we used is to introduce parallel computing techniques for the simulations. All computations were conducted using 64 processors on an IBM SP RS/6000 supercomputer. Previous study has shown that the TOUGH2_MP may achieve a linear speedup or even super- 
linear speedup (Wu et al., 2002). In addition, we also used the constant-volume approach to improve the simulation convergence rate. Using constant volume for all elements can dramatically speed up simulations. Note that the volume of elements does not affect the final, steady-state solutions.

\section{SIMULATION RESULTS AND ANALYSIS}

Five simulation cases were run with different matrix rock permeabilities and different infiltration rates. In the first case, matrix blocks with the original permeabilities were considered. This case may reflect the minimum flow-focusing situation for the fracture network. In the second case, one-tenth of the original permeabilities is applied to the matrix blocks. The results of this simulation are useful for examining the influence of matrix rock on flow focusing. In the first two cases, an infiltration rate of $5 \mathrm{~mm} / \mathrm{year}$ is applied on the top of the fracture network. The other three cases neglect the matrix rock influence or consider it as impermeable. Three different infiltration rates with $5 \mathrm{~mm} /$ year, $50 \mathrm{~mm} /$ year and $500 \mathrm{~mm} /$ year are applied to the top of the fracture network for the three cases.

\subsection{Effects of the Rock Matrix}

Flow paths are determined by the water flux magnitude presented in four different colors: blue, green, red and grey. Each color represents a one-order-of-magnitude difference in flux. For example, the blue color represents the highest water flux, about three orders higher than the grey one. We use this same coloring scheme for all simulation results. 
Figure 3 shows the simulated flux distribution in the fracture network for the first case. The flow generally proceeds in vertical fractures without clear continual flow paths developed in fractures of TSw31, TSw32 and TSw33. The flux inside fractures is not well focused through these three units. Flow in TSw34 demonstrates some focusing, which is clearly controlled by the flow paths in the TSw33. In this case, all flow-conducting fractures have similar flux. This uniformity indicates that the matrix rock has made an important contribution to flow-path development. Matrix rock can act as a bridge for flow between discontinuous fractures. Simulation results indicate that about $79 \%$ of the total flux is drained out the bottom of the domain through fractures, with only $21 \%$ of the flux flowing through matrix rock. Fractures play a dominant role in water percolation, even though the volume of fractures account for only a tiny portion of the pore space of the flow domain.

Figure 4 shows the simulation result of steady-state flux distribution in the fractures for the case with one-tenth of the original matrix rock permeabilities. In this case, flow paths are mainly controlled by fracture networks in the TSw32 and TSw33 units. Compared to the first simulation scenario, fracture flow in this case shows more focusing. Some green or blue flow paths can be seen inside the TSw32 and TSw33 units. Nine flow paths have developed at the bottom of the domain. Because unsaturated flow in fractures is gravity dominated (Liu et al., 1998), flow paths are generally vertical. Matrix also provides bridges for disconnected fractures (in the vertical direction). Subhorizontal fractures may provide pathways for flow between vertical paths. In TSw32 and TSw33, flows are mainly along fractures with large trace length, even though fractures with small trace length may also be part of the flow paths, especially those located near 
intersections. In this case, about $87 \%$ of the flux is drained out the bottom of the domain through fractures and only $13 \%$ of the flux through matrix rock. This simulation indicates that the fractures control the flow system through lower permeable matrix blocks.

\subsection{Effects of Infiltration Rates}

Flow patterns in fracture networks may also be influenced by the infiltration rate on its top boundary. Three schemes are designed for testing the influence of different infiltration rates on flow paths. Figure 5, 6, and 7 show flow paths within the unsaturated fracture network for infiltration rates of $5 \mathrm{~mm} / \mathrm{year}, 50 \mathrm{~mm} / \mathrm{year}$, and $500 \mathrm{~mm} / \mathrm{year}$, respectively. In these cases, rock matrix has been considered to be impermeable. Flow is along fractures only, and no fracturematrix interaction considered. At the upper part, several flow paths are developed from the top infiltration. These then either merge or remain separate as water continues to migrate downward. Only two primary flow paths are developed in these cases. The three cases have an almost identical flow pattern, except for differences in flux magnitude and the spreading range in the TSw34 and TSw35 units. A higher infiltration rate on the top boundary leads to a larger spreading flow-path in these units. We can conclude from these cases that the influence of infiltration rates on the flow pattern and focusing is not significant for a given fracture network.

Flow paths are controlled mainly by connected fractures. Examining globally connected fracture networks, we find that at least four connected paths exist from top to bottom. However, not all connected paths can develop into flow paths. In the upper part of the unsaturated fracture network, flow paths consist primarily of fractures that have relatively long trace lengths. Similar 
phenomena have been reported by Liu et al. (2002). In the upper part, fractures have a relatively lower density. However, this phenomenon may not exist in a higher-density fracture network. In the lower part of the fracture network, the long and short fractures make similar contributions to the development of flow paths. This finding is consistent with the study of de Dreuzy et al. (2001) which found that fracture connectivity in a fracture network is a function of fracture density and fracture length range. When fracture density is high, the contribution of fracture length to the network connectivity lessens. Fracture-network connectivity is one of the most important parameters determining flow path development. Only connected fractures can develop into a flow path.

Simulated flow patterns support the hypothesis of Liu et al. (2002) that average spacing between paths in a layered system tends to increase with depth as long as flow is gravity driven. They gave the synthetic example (Figure 8) of a geological medium consisting of three layers involving a downward unsaturated flow process. In this fracture network, both the top and bottom layer have 10 connected vertical fractures, with the middle layer having two. Because of the limitation on connected fracture numbers in the middle layer, Liu et al. (2002) believe that only two flow paths can be developed in the bottom layer, even though there are 10 vertically connected paths in that layer. Our simulation results have demonstrated a similar behavior. In Tsw31 unit, about several tens of flow paths are developed. The flow paths reduce to less than 10 in Tsw32 and two in Tsw33. Tsw34 has very high fracture density and more connected fracture paths. However, owing to the limitation of flow paths in Tsw33, only two major flow paths develop in Tsw34. Since vertical water flow has a certain degree of horizon dispersion, each flow path at the bottom of the Tsw34 unit spreads over a range of 10 to $20 \mathrm{~m}$. Simulation results 
from this study thus tend to further confirm that flow-path development in a layered, unsaturated fracture network is depth dependent, as long as gravity is the dominant driving force of the flow.

\subsection{Flow Focusing Analysis}

Modeling flow focusing is motivated by the needs of performance analysis for the Yucca Mountain repository site. Previous studies in general use stochastic fracture-continuum model (Bodvarsson et al. 2003) or dual-permeability models to conceptualize the fractured rock at the site. These models have difficulty capturing the phenomena of highly localized flow focusing and discrete features of flow paths in individual fractures, while our discrete fracture model provides an effective approach for insight into flow within each fracture.

Figure 9 shows the vertical liquid mass flux in both fracture and matrix rock along the bottom boundary for the original permeability case and the one-tenth original permeability case. The figure shows a significant variability in flux. For both cases, flux in the matrix has values ranging from 0 to about $4 \times 10^{-7} \mathrm{~kg} / \mathrm{s}$; flux in fractures range from 0 to about $1.2 \times 10^{-6} \mathrm{~kg} / \mathrm{s}$. By projecting the flux in fractures to their corresponding matrix blocks, the distribution of total flux along the bottom boundary can be estimated. Total flux distribution (Figure 9) indicates the development of about 30 discrete flow paths over the $100 \mathrm{~m}$ boundary length. The flux magnitude of these flow paths changes significantly from fracture to fracture, and most of the fluxes focus in a few paths. By comparing the total flux distribution in Figure 9(a) and (b), we find that flow path distributions for the two cases are similar. However, some differences appear in flow-focusing magnitude. 
The flow-focusing phenomena are evaluated through frequency distribution of normalized percolation fluxes along the bottom boundary. Normalized percolation fluxes are determined by normalizing the total flux to the infiltration rate $(5 \mathrm{~mm} / \mathrm{year})$ on the top boundary. Figure 10 shows the area frequency distribution of the two cases. The figure indicates that the majority of fluxes are in flow paths having low normalized fluxes, ranging from 0 to 2 , with the remaining fluxes being low-frequency, high normalized fluxes. This result is consistent with the conclusion of a previous flow-focusing study using stochastic fracture-continuum models by Bodvarsson et al. (2003). The maximum flux that occurs in the system is about 5-10 times more than the infiltration flux prescribed at the top boundary. This higher normalized flux is caused by the high flux rates in several fracture flow paths. Note that the normalized flux is computed by projecting fracture flow to its corresponding matrix block. Fracture flux can be much higher than the infiltration rate and its area frequency can be much lower. Comparing the flux frequency distribution of the two simulation cases, we can conclude that lower matrix rock permeability will lead to a greater flow-focusing phenomenon.

Figure 11 shows the vertical flux distribution along the bottom boundary for the three simulation cases with different infiltration rates on the top boundary. The three simulations produce very similar flux distribution at the domain bottom, except for some differences in flux magnitude within fractures. Because of neglecting the influence of the matrix rock in these simulations, flow is focused into a few fractures and forms two main flow paths. The two flow paths spread over a range of $8.7 \mathrm{~m}(17.3 \mathrm{~m}-26.0 \mathrm{~m})$, and $5.6 \mathrm{~m}(56.2 \mathrm{~m}-61.9 \mathrm{~m})$, respectively. An average flow focusing-factor can be estimated by dividing the total length of the top boundary by the 
total spreading range. The average flow-focusing factor from the current models is approximately seven, which indicates that the average flux in the flow paths is about seven times higher than the infiltration rate on the top of the model domain. Note that the calculations for flow-focusing factor are based on the flow spreading range, which can only be an average value; flux in specific fractures can be much higher than the average value. By examining the flux distribution of the three simulations, we may conclude that infiltration rate is not an important factor for flow focusing in an unsaturated fracture network.

\section{SUMMARY AND CONCLUSIONS}

Numerical studies have been conducted to investigate the development of discrete-fracture flow paths and flow-focusing phenomena in a two-dimensional, large-scale discrete-fracture network. The fracture network is constructed using field-measured fracture data from the unsaturated rock of the potential repository horizon at Yucca Mountain, Nevada. These modeling studies examine the basic flow-focusing phenomena through discrete unsaturated fractures, and the influences of matrix permeability and infiltration rate on flow path development and flow focusing.

This paper presents a methodology for the construction of a discrete-fracture network based on field-measured fracture data. The proposed approach represents the field-measured fracture distribution by randomly generating fractures conditioned via statistical information from field measurement data, including fracture density, trace lengths, and orientations. Each fracture in the network is randomly distributed. Statistical properties of generated fracture networks reflect the corresponding properties of fracture distribution measured in the study domain. 
Rrandomly distributed fractures can lead to an extremely complex and large unstructured grid and create irregular and multiple element connections and elements that may have a large difference in volume. All these may cause numerical difficulties and require intensive computational efforts in simulations. In this work, we use high-resolution grids to capture the complexity of the discrete-fracture network. Several numerical techniques are used for handling the complex-global-grid connections system. Of the techniques tested, massively parallel computing has proven to be the most efficient.

These modeling results further demonstrate that focused flow paths through fractures are generally vertical. Horizontal fractures mainly behave as pathways between neighboring vertical fractures. Contribution of the fracture network to flow-focusing phenomena may be greatly influenced by the matrix permeability of the surrounding rock. Lower rock-matrix permeability will lead to more flow focusing. Simulation results suggest that the average spacing between flow paths in a layered system tends to increase with depth, or that flow becomes more focused with the increase in depth as long as flow is gravity driven. In addition, flow paths are found to consist primarily of long trace fractures in lower fracture-density domains. In higher fracturedensity domains, long and short trace fractures both contribute to the development of flow paths.

In summary, the majority of fluxes along flow paths have low normalized fluxes (ranging from 0 to 2) for the case that considers matrix block influence. The maximum flux that occurs in the system is about 5-10 times more than the infiltration flux value prescribed at the top boundary. The higher normalized flux is caused by the higher degree of focusing into several fracture paths. 
Simulation results indicate that lower matrix-rock permeability will lead to a higher flowfocusing phenomenon. For the case of impermeable matrix blocks, flow focuses in several fractures and forms two main flow paths. These two flow paths spread a range of $8.7 \mathrm{~m}$ and 5.6 $\mathrm{m}$ respectively. The average flux in the flow paths is about seven times higher than the infiltration rate at the top of the model domain. Simulation results also reveal that the impact of infiltration rate on flow focusing is insignificant for unsaturated flow in a fracture network.

\section{ACKNOWLEDGMENTS}

The authors would like to thank Yongkoo Seol and D. Hawkes for their critical reviews of the manuscript. This work was supported by the Director, Office of Civilian Radioactive Waste Management, U.S. Department of Energy, through Memorandum Purchase Order EA9013MC5X between Bechtel SAIC Company, LLC, and the Ernest Orlando Lawrence Berkeley National Laboratory (Berkeley Lab). The support is provided to Berkeley Lab through the U.S. Department of Energy Contract No. DE-AC03-76SF00098.

\section{REFERENCES}

Bodvarsson, G.S., Y.S. Wu, and K. Zhang, 2003, Development of discrete flow paths in unsaturated fractures, accepted for publication in J. Contaminant hydrology.

Chilès, J.P., and G. de Marsily, 1993, Stochastic modeling of fracture systems and their use in flow and transport modeling, In J. Bear, C.F. Tsang and G. de Marsily (eds.), Flow and Contaminant Transport in Fractured Rock, San Diego, California: Academic Press. 
De Dreuzy, J.R., P. Davy, O. Bour, 2001, Hydraulic properties of two-dimensional random fracture networks following a power law length distribution 1. Effective connective, Water Resources Research, 37(8): 2065-2078.

de Marsily, G., 1986, Quantitative Hydrogeology, Academic Press, San Diego, CA.

Finsterle, S. 2000. Using the continuum approach to model unsaturated flow in fractured rock. Water Resources Research, 36(8): 2055-2066.

Fabryka-Martin, J. T., P.R. Dixon, S. Levy, B. Liu, H.J. Turin, and A.V. Wolfsberg, 1996. Systematic Sampling for Chlorine-36 in the Exploratory Studies Facility. LA-CST-TIP-96001, Milestone 3783AD, Los Alamos National Laboratory, Los Alamos, New Mexico.

Gauthier, J. H., M.L. Wilson, F.C. Lauffer, 1992, Estimating the consequences of significant fracture flow at Yucca Mountain. Proceedings, Third Annual International High-Level Radioactive Waste Management Conference, Las Vegas, NV, Vol. 1, pp. 891-898, American Nuclear Society, La Grange Park, IL, April 1992.

Kwicklis, E.M., and R.W. Healey, 1993, Numerical investigation of steady liquid water flow in a variably saturated fracture network, water Resour. Res., 29(12), 4091-4102.

Liu, H.H., and G.S. Bodvarsson, 2001, Constitutive relations for unsaturated flow in a fracture network, Journal of Hydrology, 252, 116-125. 
Liu, H.H., G.S. Bodvarsson, and S. Finsterle, 2002, A note on unsaturated flow in twodimensional fracture networks, Water Resour. Res., 38(9), 1176-1184.

Persoff, P., K. Pruess, 1995, Two-phase flow visualization and relative permeability measurement in natural rough-wall rock fractures. Water Resur. Res., 31(5), 1175-1186.

Peters, R.R., Klavetter, E.A., 1988, A continuum model for water movement in an unsaturated rock mass. Water Resour. Res., 24(3), 416-430.

Pruess, K., 1991. TOUGH2 - A general-purpose numerical simulator for multiphase fluid and heart flow. Report LBNL-29400, Lawrence Berkeley National Laboratory, Berkeley, California.

Pruess, K., 1998, On water seepage and fast preferential flow in heterogeneous, unsaturated rock fractures. J. Contaminant hydrology, 30, 333-362.

Pruess, K.A., 1999. Mechanistic model for water seepage through thick unsaturated zones of fractured rocks of low permeability. Water Resources Research, 35(4): 1039-1052.

Pruess, K., and Y.W. Tsang, 1990, On two-phase relative permeability and capillary pressure of rough-walled rock fractures. Water Resour. Res., 26(9), 1915-1926.

Rasmussen, T., 1987. Computer simulation model for steady fluid flow and solute transport through three-dimensional networks of variably saturated, discrete fractures. In: Evans, D., 
and T. Nicholson (Eds.), Flow and Transport through Unsaturated Fractured Rock, American Geophysical Union, Geophysical Monograph 43: 107-114.

Sudicky, E.A., and R.G. McLaren, 1992, The Laplace transform Galerkin technique for largescale simulation of mass transport in discretely fractured porous formations. Water Resour. Res., 28(2), 499-514.

Therrien, R., and E.A. Sudicky, 1996, Three-dimensional analysis of variably-saturated flow and solute transport in discrete0fractured porous media, J. Contam. Hydrol., 23, 1-44.

van Genuchten, M. Th., 1980. A closed-form equation for predicting the hydraulic conductivity of unsaturated soils. Soil Sci. Soc. Amer. J, 44(5): 892-898.

Warren, J.E. and P.J. Root, 1963. The behavior of naturally fractured reservoirs. Soc. Pet. Eng., Trans. SPE of AIME, 228: 245-255

Wu, Y.S., C. Haukwa, and G.S. Bodvarsson, 1999. A site-scale model for fluid and heat flow in the unsaturated zone of Yucca Mountain, Nevada. Journal of Contaminant Hydrology, 38(1-3): $185-217$.

Wu, Y.S., K. Zhang, C. Ding, K. Pruess, E. Elmroth, and G.S. Bodvarsson, 2002, An efficient parallel-computing method for modeling nonisothermal multiphase flow and multicomponent transport in porous and fractured media. Advances in Water Resources, 25, 243-261. 
Zhang, K., and A. Woodbury, 2002, A Krylov finite-element approach for multi-species contaminant transport in discretely fractured porous media, Advances in Water Resources, 25, $705-721$.

Zhang, K., Y.S. Wu, C. Ding, K. Pruess, and E. Elmroth, 2001. Parallel computing techniques for large-scale reservoir simulation of multicomponent and multiphase fluid flow. Paper SPE 66343, Proceedings of the 2001 SPE Reservoir Simulation Symposium, Houston, Texas.

Zimmermann, R.W. and G.S. Bodvarsson, 1996. Effective transmissivity in two-dimensional fracture networks, Int. J. Rock Mech. Min. Sci. 33(4): 433-438. 


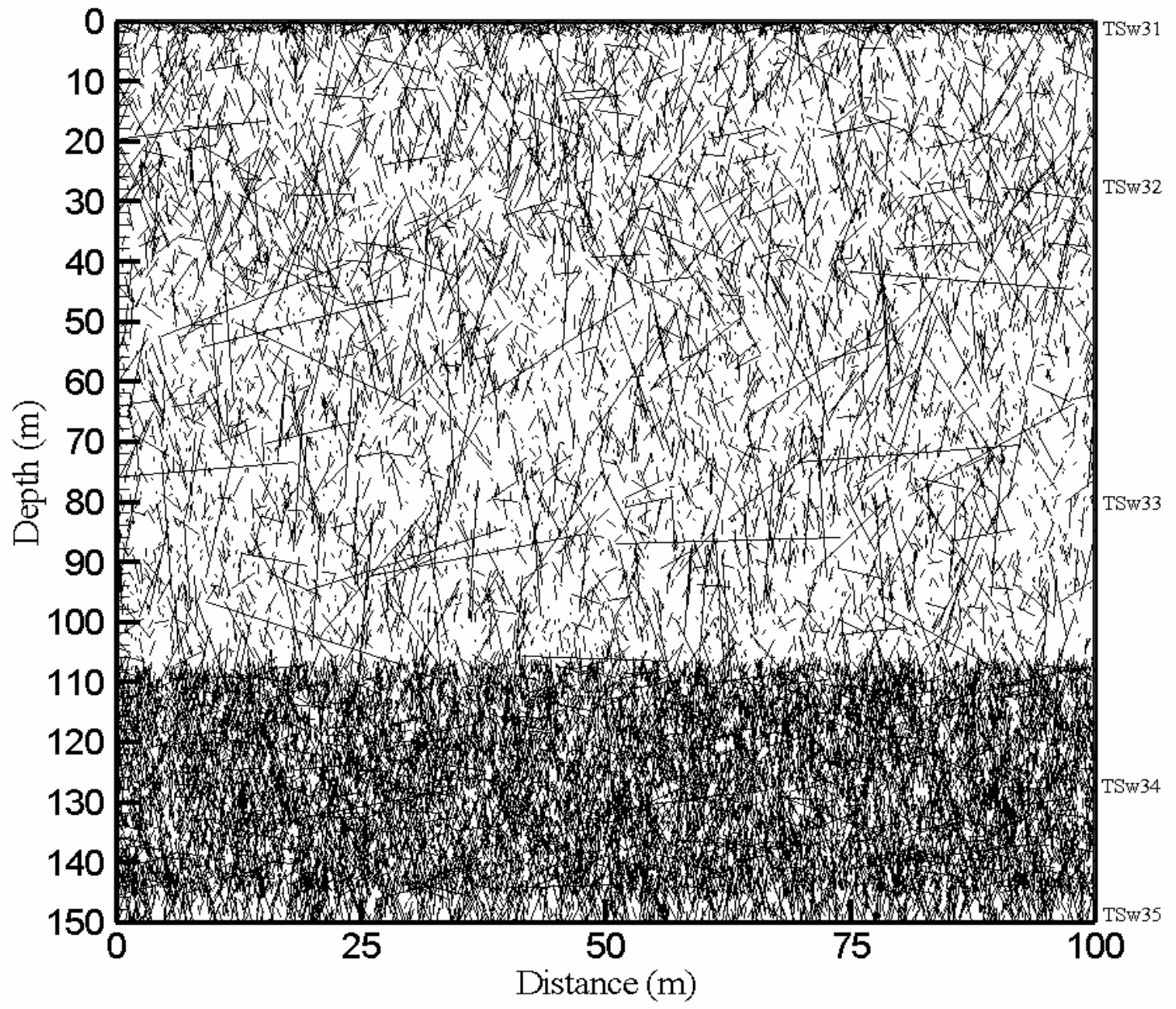

Figure 1. A fracture network generated based on statistical information derived from the field measured fracture data from Yucca Mountain site. 


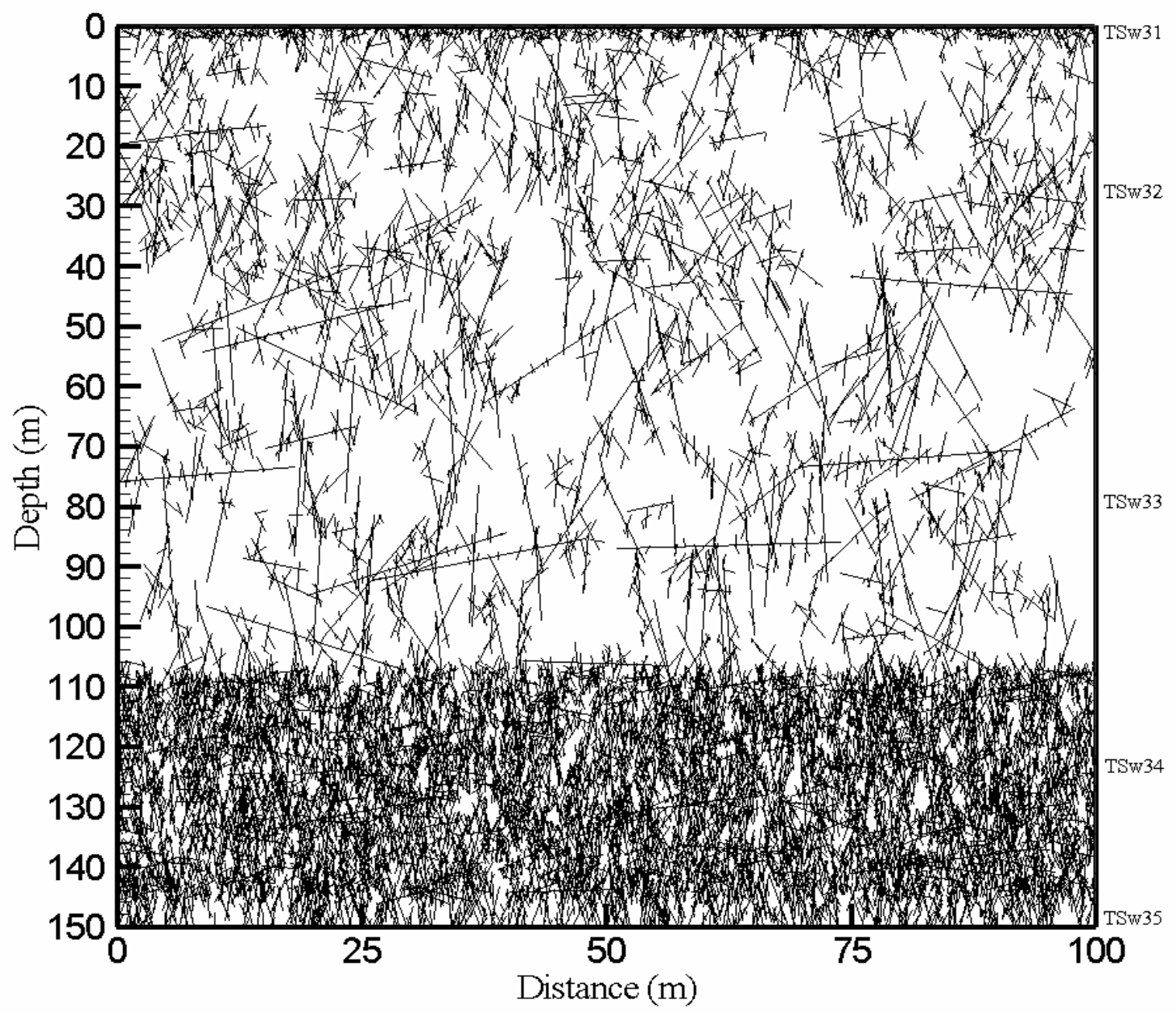

Figure 2. The generated fracture network, excluding non-connected fractures. 


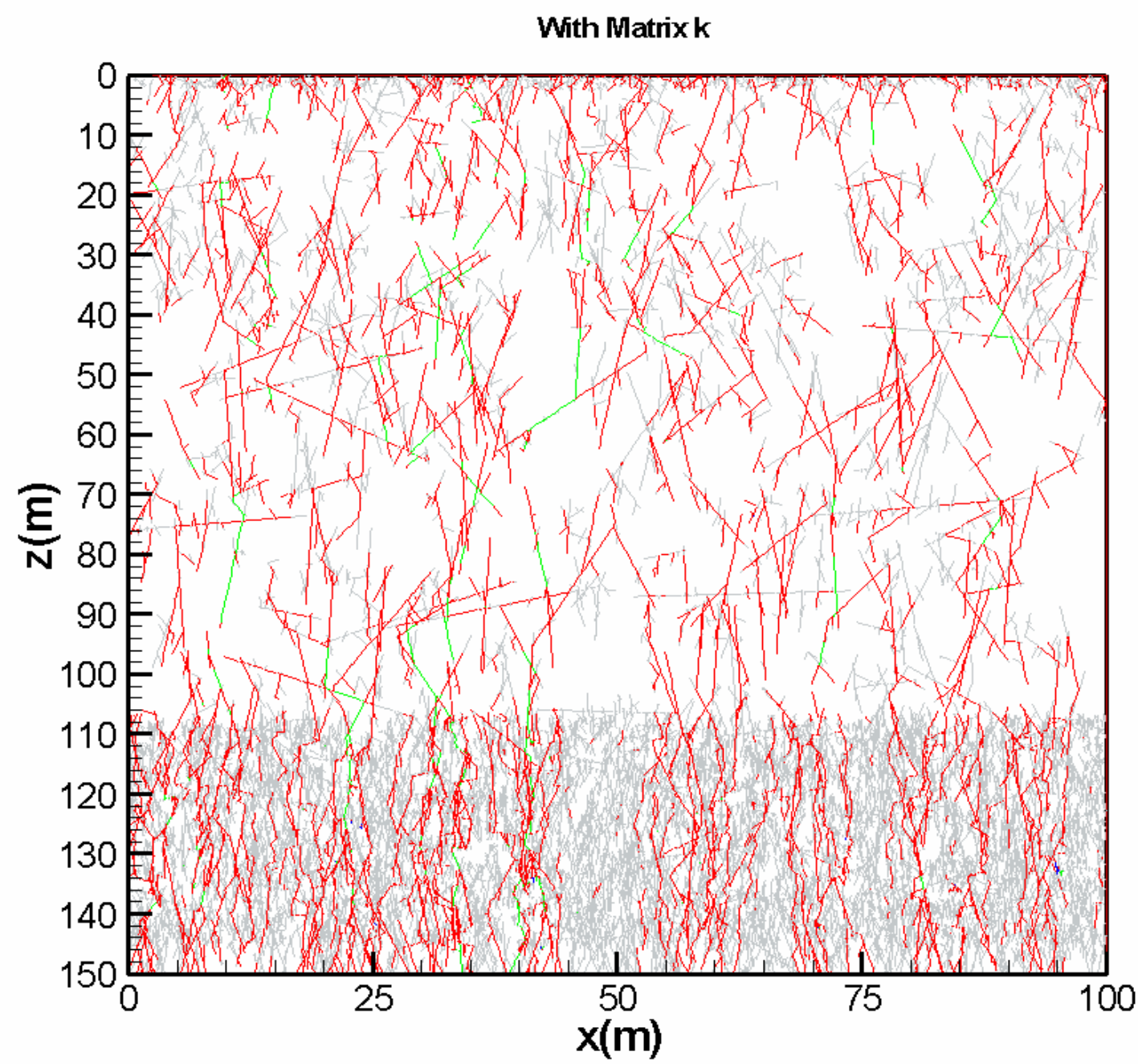

Figure 3. Simulated steady state flux distribution in the fracture network (matrix permeability $=\mathrm{k} ; \mathrm{q}=5 \mathrm{~mm} / \mathrm{year}$. Flux magnitude is represented in four different colors in decreasing sequence of blue, green, red and grey. Each color represents one-order-ofmagnitude difference in flux). 


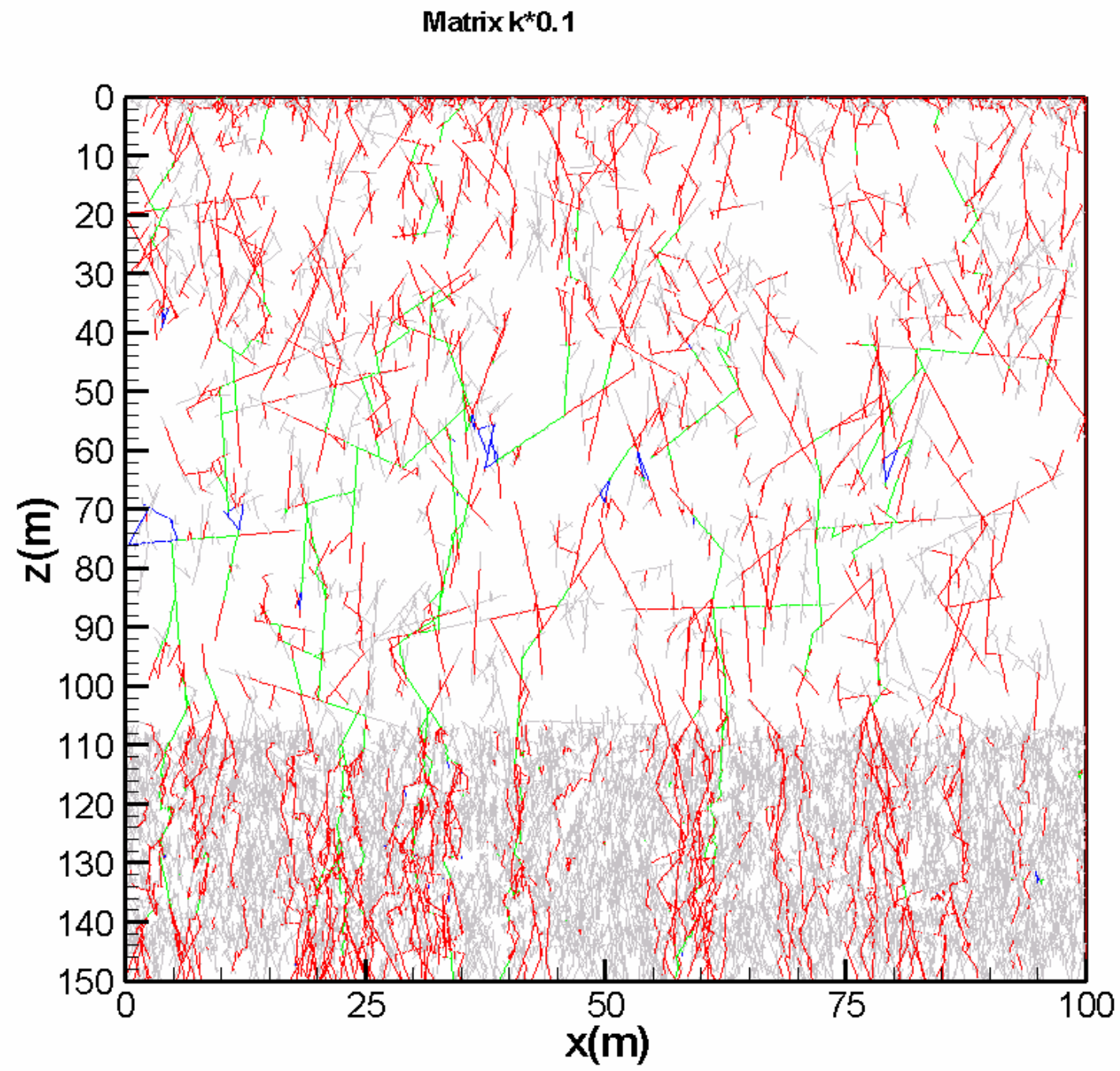

Figure 4. Simulated steady state flux distribution in the fracture network (matrix permeability $=\mathrm{k}^{*} 10 \% ; \mathrm{q}=5 \mathrm{~mm} /$ year). 


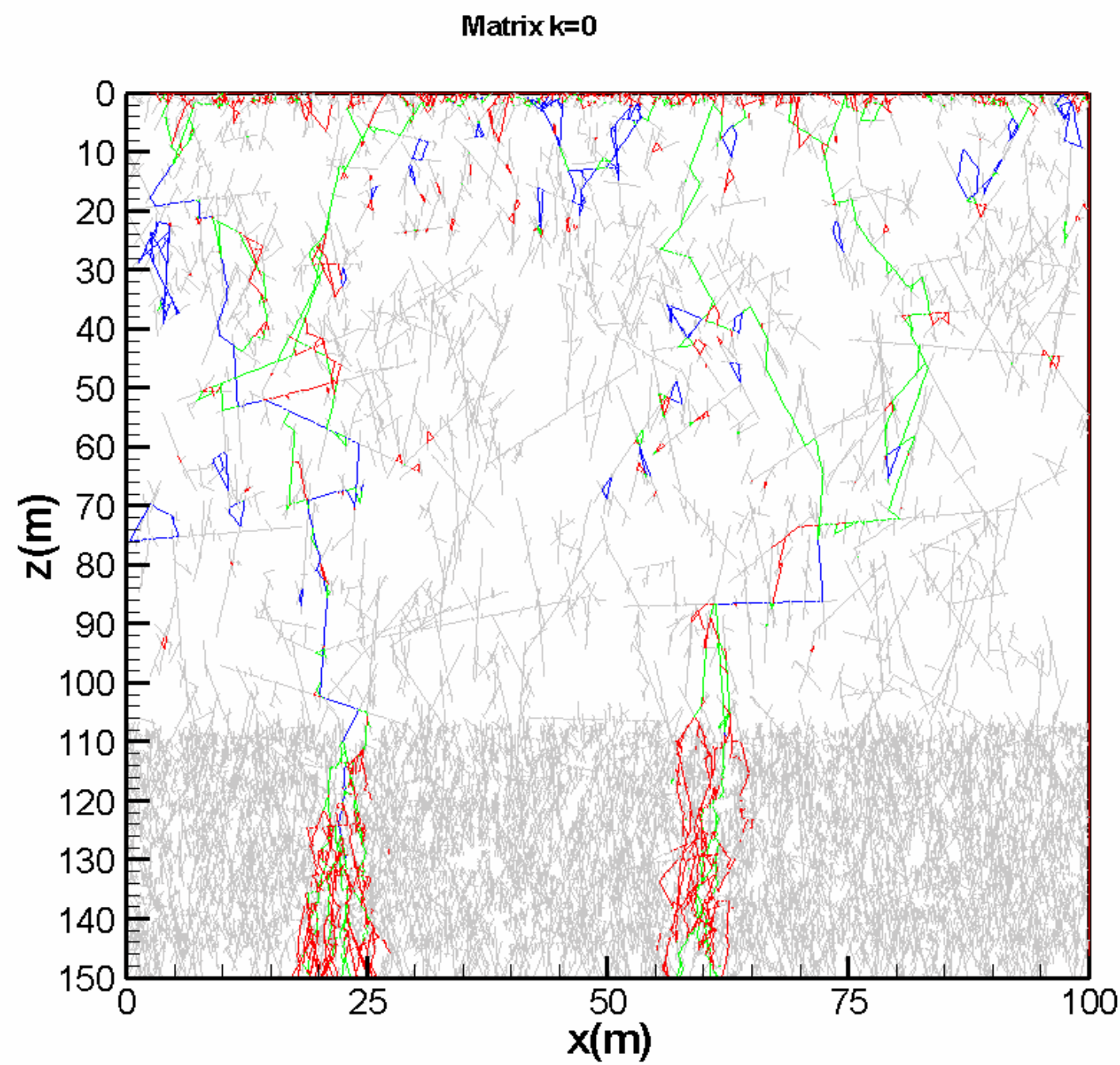

Figure 5. Simulated steady state flux distribution in the fracture network (matrix permeability=0; $\mathrm{q}=5 \mathrm{~mm} /$ year). 


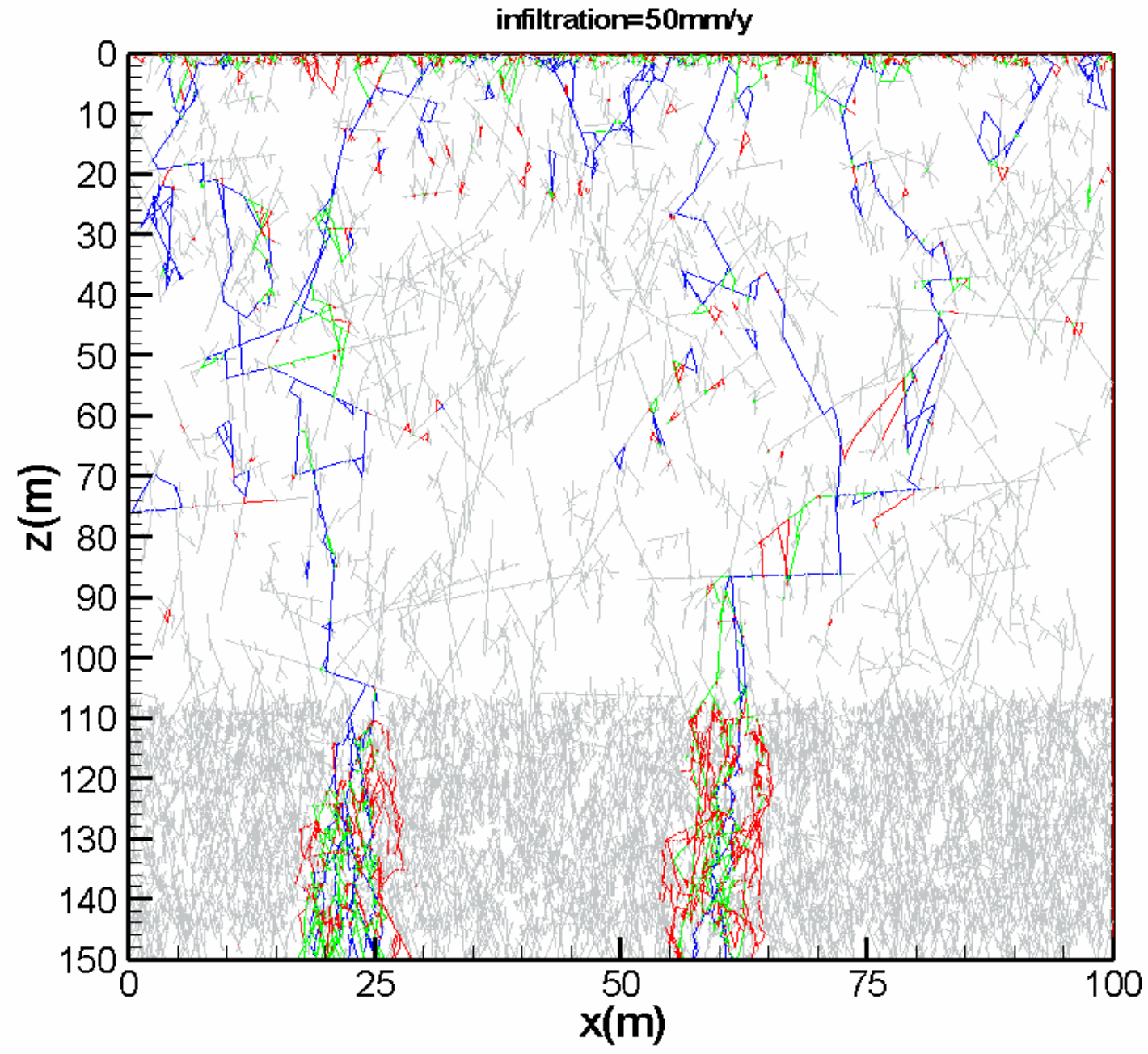

Figure 6. Simulated steady state flux distribution in the fracture network (matrix permeability $=0 ; \mathrm{q}=50 \mathrm{~mm} /$ year). 


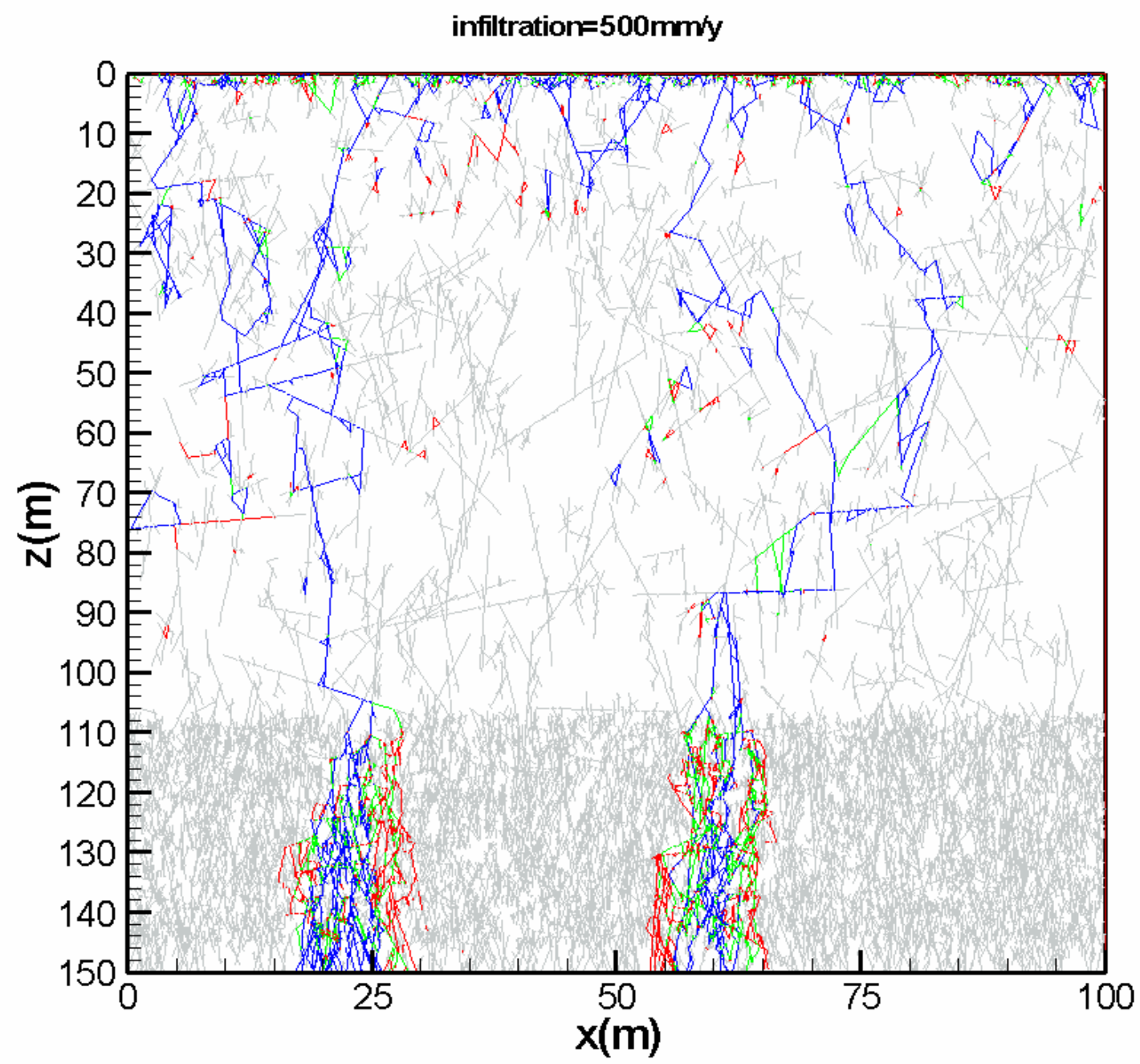

Figure 7. Simulated steady state flux distribution in the fracture network (matrix permeability $=0 ; \mathrm{q}=500 \mathrm{~mm} /$ year). 


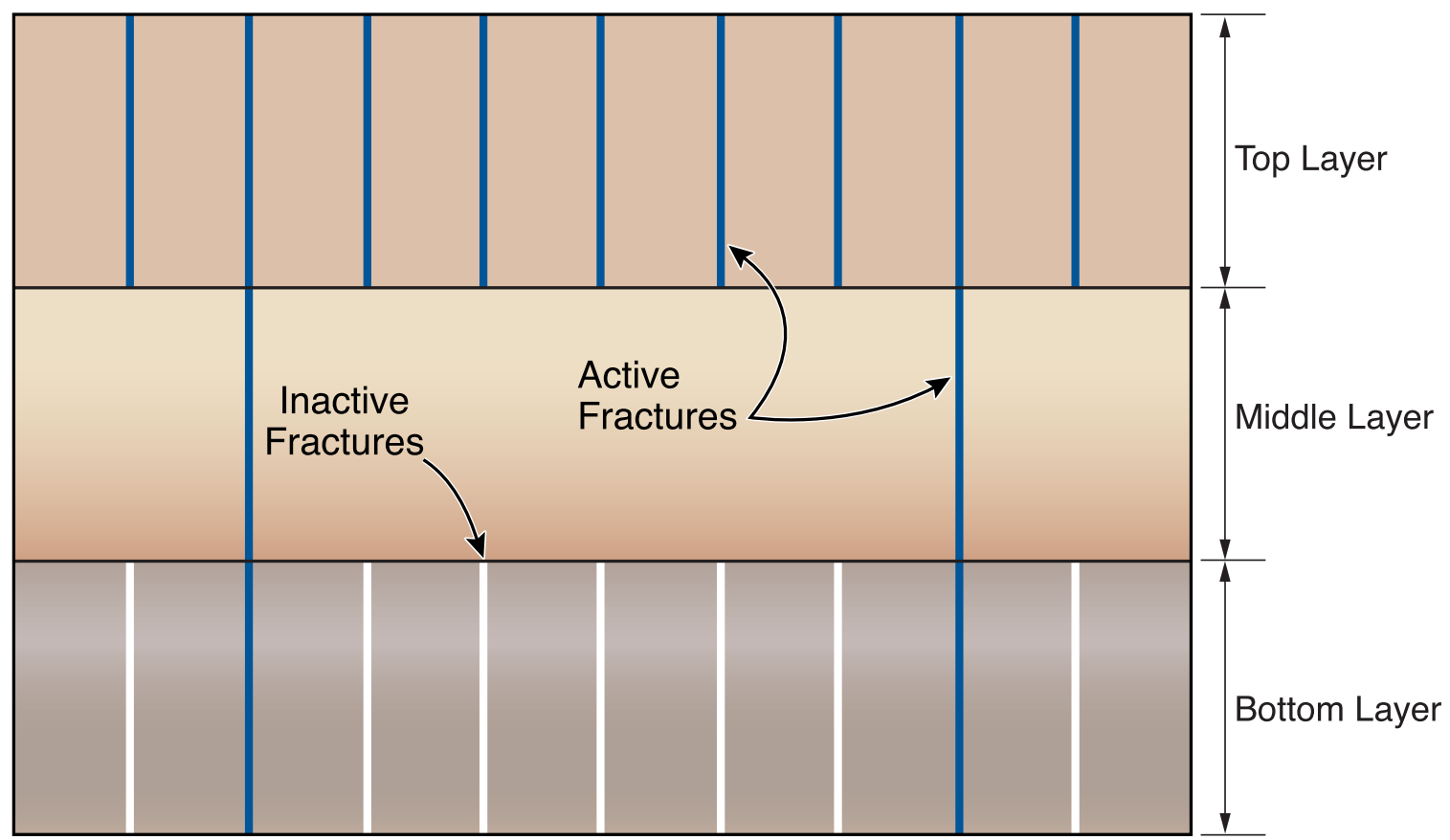

Figure 8. A schematics to demonstrate a hypothesized flow-focusing mechanism in fracture networks for layered geologic media (from Liu et al., 2002) 


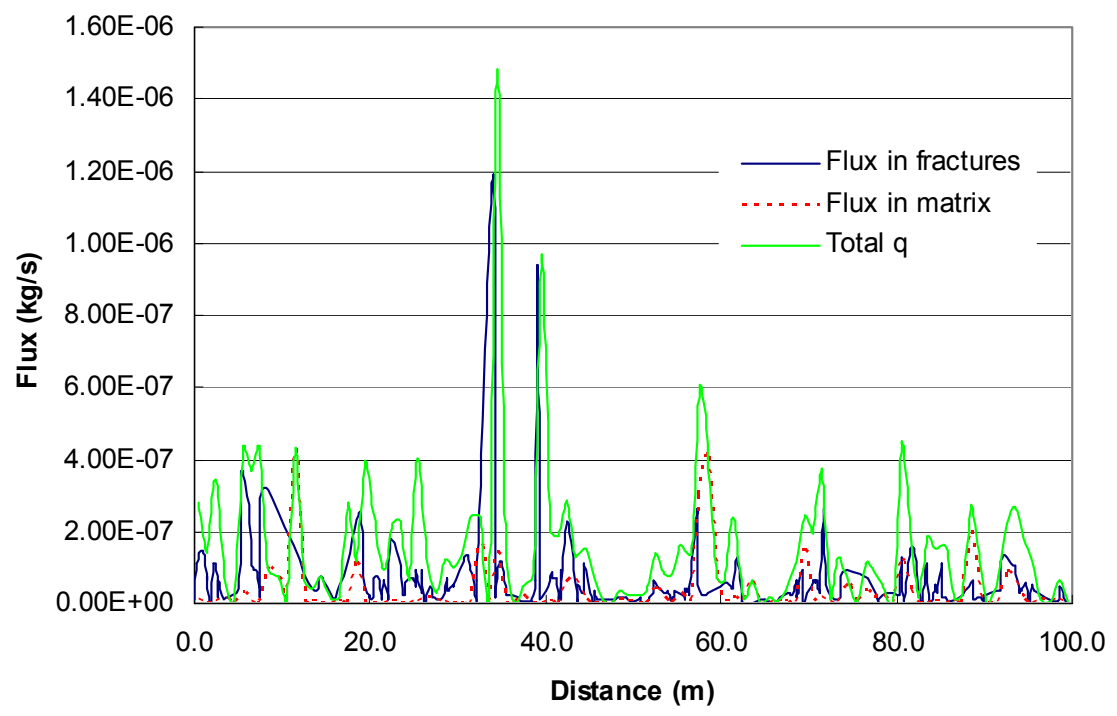

(a)

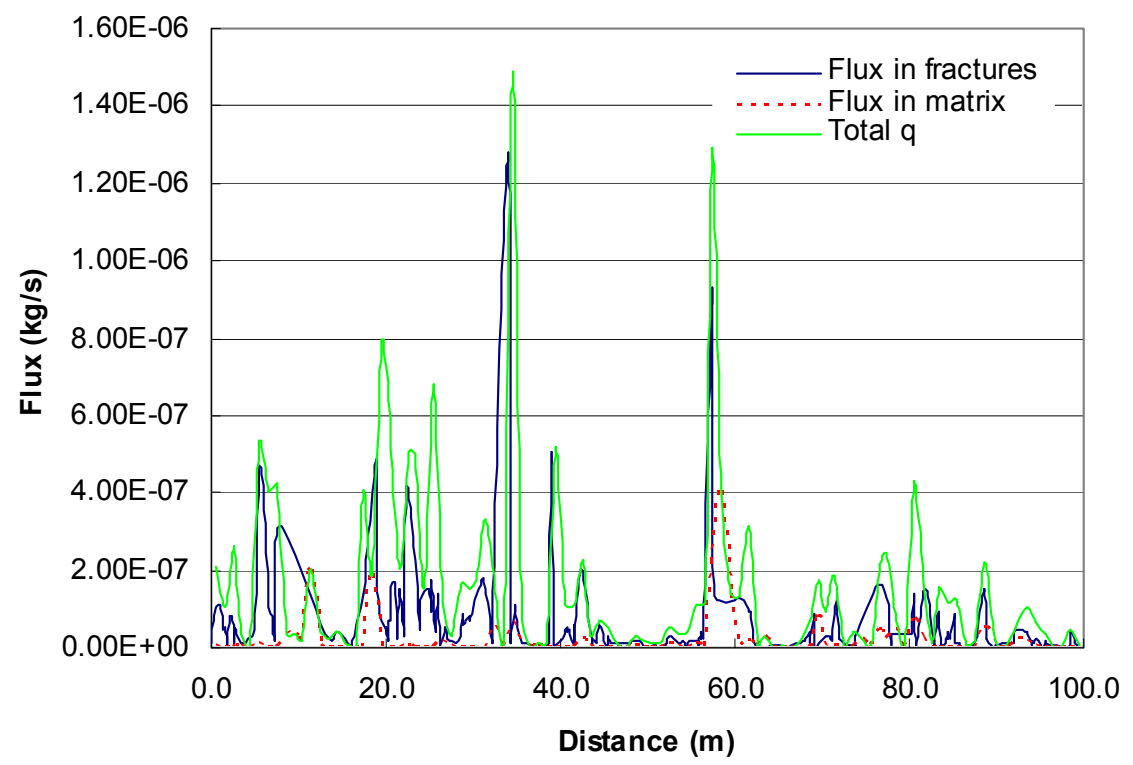

(b)

Figure 9. Vertical flux distribution along bottom boundary. (a) with K; (b) with $\mathrm{K}^{*} 10 \%$ 
Flux frequency distribution

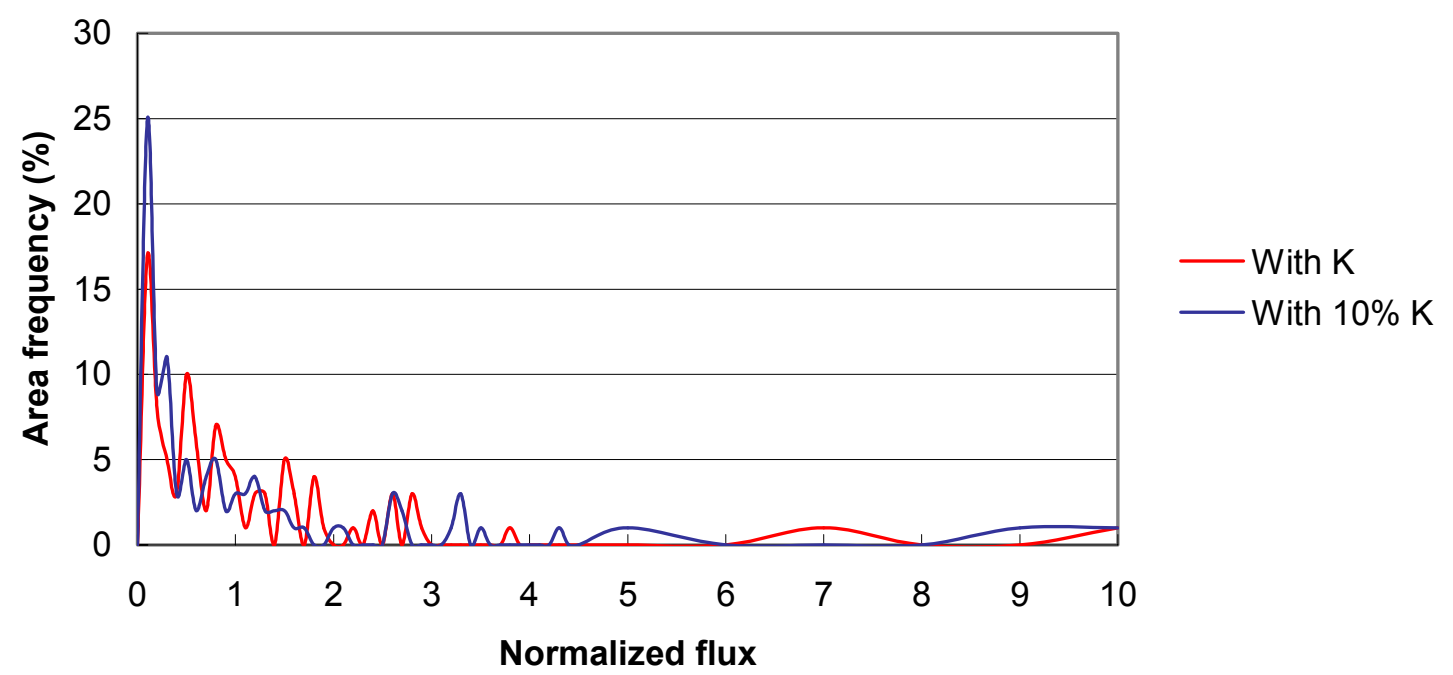

Figure 10. Flux area frequency distribution along bottom boundary. 


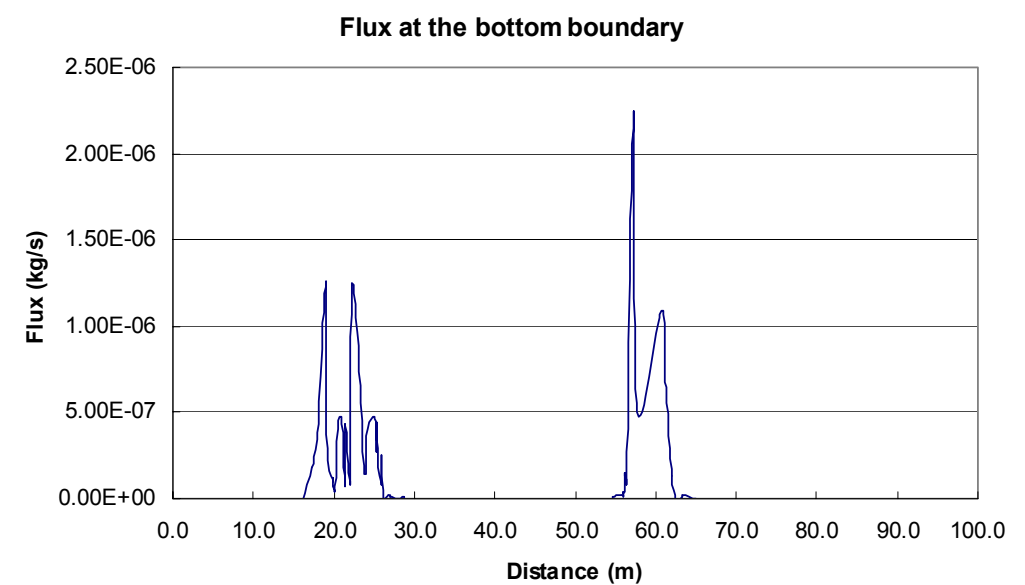

(a)

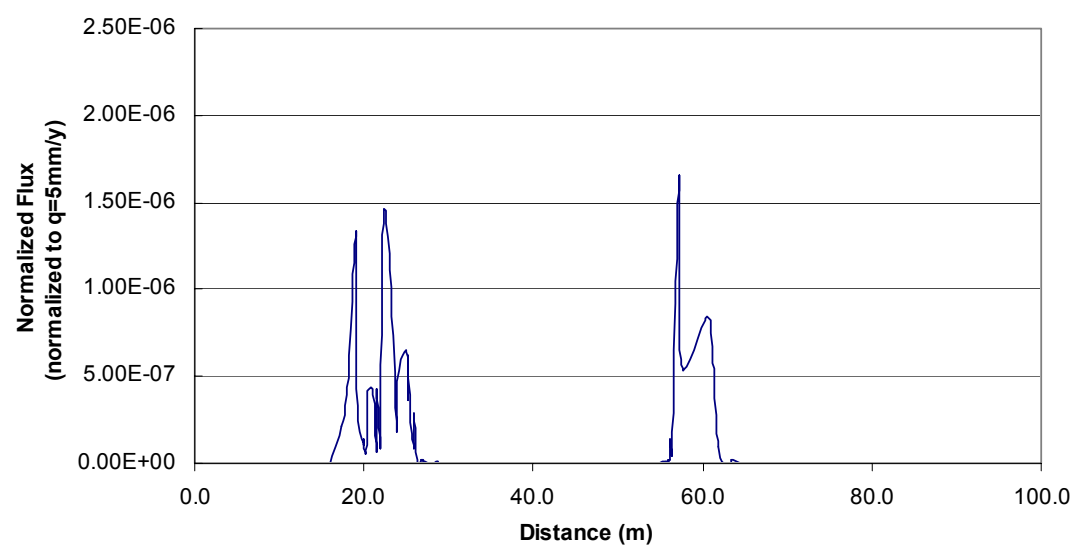

(b)

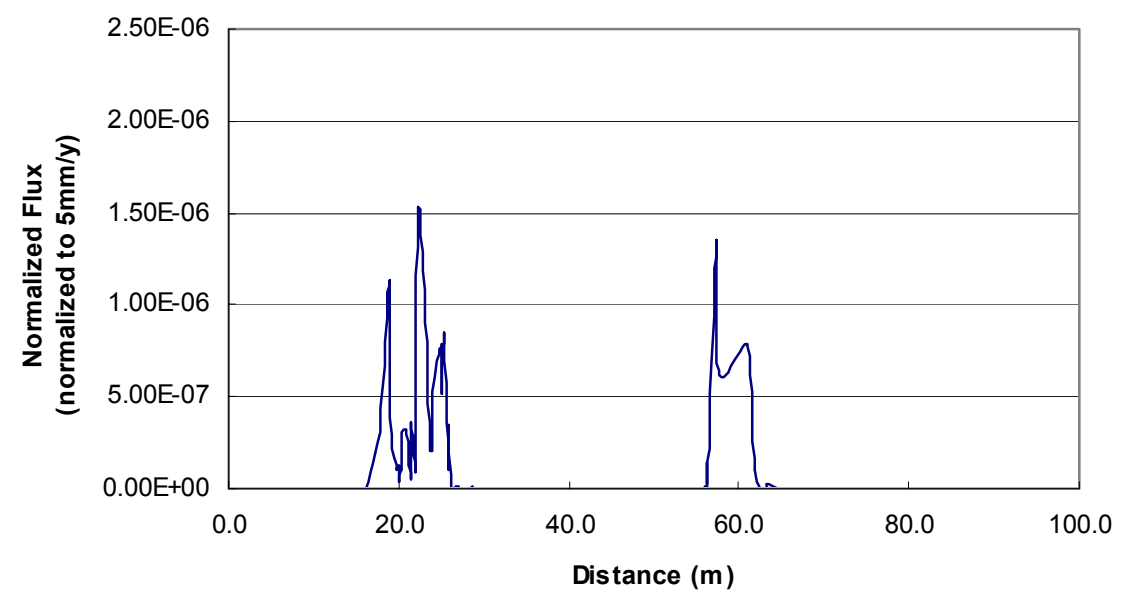

Figure 11. Vertical flux distribution along bottom boundary. (a) $K=0, q=5 \mathrm{~mm} / \mathrm{y}$; (b) $\mathrm{K}=0$, $\mathrm{q}=50 \mathrm{~mm} / \mathrm{y}$; (c) $\mathrm{K}=0, \mathrm{q}=500 \mathrm{~mm} / \mathrm{y}$. 